\title{
The U se of $\mathrm{O}$ n-line Capillary E lectrophoresis/ E lectrospray Ionization with D etection via an Ion Trap Storage/R eflectron Time-of-flight Mass Spectrometer for R apid M utation-site A nalysis of Hemoglobin Variants
}

\author{
Michael $X$. L $i, J$ ing-Tao Wu, Lin Liu, and D avid M. L ubman* \\ Department of Chemistry, The U niversity of M ichigan, A nn A rbor, MI 48109-1055, U SA
}

SPONSOR REFEREE: Dr R obert D. Voyksner, R esearch Triangle Institute, 3040 Cornwallis R oad, R esearch Triangle Park, N.C. 27709-2194, U SA.

\begin{abstract}
Capillary electrophoresis/electrospray ionization using an ion trap storage/reflectron time-of-flight mass spectrometer detector (CE/E SI-IT/reTOF) is used to provide a rapid and sensitive method for analyzing structural variants in the hemoglobin $(\mathrm{H} \mathrm{b}) \beta$-chain. The $\mathrm{Hb} \alpha$ - and $\beta$-chains are separated and the $\beta$-chain is digested by trypsin. The digest is analyzed by CE/ESI-IT/reTOF where a comparison of the total ion electrophorograms and mass spectra of the mutant and normal hemoglobins ( $\mathrm{H}$ bs) can detect the presence of a mutation site. In addition, collision-induced dissociation in the vacuum interface - skimmer region can be used to pinpoint the identity of such a site. The unique capability of the CE/E SI-IT/reTOF system for accurately detecting fast separations with narrow peaks that may be under $1 \mathrm{~s}$ full width at half maximum is demonstrated. The speed of this system is essential for resolution of the large number of peaks that are separated in a short time duration using CE separations. ๑ 1997 by John Wiley \& Sons, Ltd.
\end{abstract}

Received 5 November 1996; A ccepted 5 N ovember 1996

Rapid Commun. M ass Spectrom. 11, 99-108 (1997)

No. of Figures: 6 No. of Tables: 1 No. of R efs: 33

Since the discovery of its first variant in 1956, ${ }^{1}$ hemoglobin $(\mathrm{Hb})$ has been an important subject for biological research and clinical practice. The presence of abnormal hemoglobins can cause severe diseases directly related to the structure of the $\mathrm{Hb}$. M ost of the more than 700 structural variants ${ }^{2}$ known to date are single amino acid substitutions in either the $\alpha$ - or $\beta$-chains, although chain elongation, deletion and other mutations may be found. The conventional detection of hemoglobinopathies relies on electrophoresis ${ }^{3}$ and isoelectrofocusing, ${ }^{4}$ which are labor intensive and time consuming, often requiring several days to complete.

$M$ ore recently, reversed-phase high-performance liquid chromatography (R P-HPLC) of either $\mathrm{Hb}$ or its tryptic digests has been used to identify $\mathrm{Hb}$ variants when the analysis time is typically under $1 \mathrm{~h} . .^{5}$ The analysis of $\mathrm{H}$ b was significantly improved by Shelton et al. ${ }^{6}$ who used large-pore $C_{4}$ columns together with simplified acetonitrile-water-trifluoroacetic acid (TFA) gradients to separate and identify the whole globin chains from normal and variant hemoglobins. A more definitive method used tryptic digestion of $\mathrm{Hb}$ with HPLC separation for identification of variant globins based upon a comparison of the tryptic fragments produced. ${ }^{7,8}$ In the tryptic fragments of $\mathrm{H}$ b there are 29 digestion peaks for normal adult hemoglobin ( $\mathrm{HbA}$ ), four of which, $\alpha \mathrm{T} 12, \alpha \mathrm{T} 13, \beta \mathrm{T} 10$, and $\beta T 12$ are insoluble and precipitate out during the digestion preparation; two other single amino acid products, $\alpha \mathrm{T} 8$

* Correspondence to: D. M. Lubman

Contract grant sponsor: National Institutes of $\mathrm{H}$ ealth; Contract grant number: R 01 G M 49500

Contract grant sponsor: U S A rmy/ER DE C; Contract grant number: DA A D 05-95-9-3517 and $\beta T 8$, are not detected with a UV absorbance detector at $200 \mathrm{~nm}^{9}$ Substitution of amino acids between normal $\mathrm{Hb}$ and one of its variants results in a change of the position and number of the fragments. The HPLC method provides an important advantage over conventional electrophoresis in terms of the time of analysis. However, HPLC is unable to efficiently resolve all peptides in $\mathrm{Hb}$ tryptic digests, and overlapping and unresolved peaks may make identification difficult. Nevertheless, much work has been done developing HPLC methods for the characterization of clinical $\mathrm{H} \mathrm{b}$ mutations. ${ }^{7}$

The recent development of capillary electrophoresis $(C E)^{10,11}$ has provided a complementary method to HPLC and gel electrophoresis. The high sensitivity and superior resolving power of CE has led to its use in solving important problems in the biological and biomedical fields. Perrett et al. ${ }^{9}$ studied the tryptic mapping of some common and rare $\mathrm{Hb}$ variants using CE separation with UV detection. They readily observed the abnormal peptide fragments which could be identified by comparison between the normal and abnormal tryptic map profiles. Various other researchers, including Casragbola ${ }^{12}$ and $O n^{13},{ }^{13}$ have used CE for the separation of globin chains in a rapid identification of variant hemoglobins where separations could be performed within 10 min.

In order to unambiguously prove the presence of a hemoglobin mutation and to identify the variant sites, mass spectrometry has been successfully combined to separation techniques such as H PLC or CE, either offline or on-line. The use of mass spectrometry in $\mathrm{Hb}$ analysis by $\mathrm{M}$ atsuo et al. ${ }^{14}$ incorporated field desorption and fast-atom bombardment mass spectrometry (FA B - 
MS) in the analysis of the tryptic digests of $\alpha-, \beta-$, and $\delta$-chains. In subsequent work, Ferranti and coworkers ${ }^{15}$ used CE separation of globin chains and tryptic digests with detection by FA B-M S to characterize hemoglobinopathies. In this work, the fractions from CE were collected and sequentially determined off-line by mass spectrometry. The obvious disadvantage of this method is that it is extremely difficult to collect the fast-eluting electrophoretic peaks, and the small sample amount was not sufficient for FA B mass analysis for some fragments. More recently, several groups ${ }^{16-19}$ have coupled microbore H PL C on-line with electrospray ionization mass spectrometry (ESI-M S) to identify various $\mathrm{Hb}$ mutations. The use of microbore columns improved the analysis time compared with previous HPLC work but is still considerably longer than the time-frame that can be achieved by using a CE separation. In addition, much improved resolution could be achieved using CE as compared to HPLC. $O$ ther mass spectrometric methods have also been used for the analysis of $\mathrm{Hb}$ variants. B iemann's group ${ }^{20}$ used matrix-assisted laser desorption/ionization time-offlight mass spectrometry (MALDI-TOFMS) without separation to analyze the proteolytic digests of the normal and cross-linked $\mathrm{Hb} \beta$-chains. 0 ther groups ${ }^{21-25}$ have used a mass spectrometer without separation, directly applying tandem mass spectrometry (M S/M S) and collision-induced dissociation (CID) on the entire $\mathrm{H} \mathrm{b}$ protein or separated $\alpha$ - and $\beta$-chains, to identify the variation sites in a series of abnormal hemoglobins. The mass analysis provides unambiguous identification for most of the fragments and confirms the variant sites inside the specific chains. H owever, the mass fragments of the entire multiply-charged $\mathrm{Hb}$ molecule result in sequence information for $\sim 29 \%$ of the molecule ${ }^{21}$ and it can only be used to confirm certain common mutations that lie within the well-known tryptic mapping regions. ${ }^{17}$ In addition, the resulting M S/M S or CID spectrum is complicated and it requires extensive calculation and comparison for accurate analysis, especially where mutations may result in a shift of only a couple of mass units.

This work reports on the analysis of globin chain digests in several variant hemoglobins using on-line CE/M S with amine-coated fused-silica capillaries where the CE anodic end was directly applied as the microelectrospray needle. The results demonstrate that using the CE capability for fast separation, combined with mass analysis, a rapid and sensitive method could be developed in the screening and detection of abnormal $\mathrm{H}$ bs. Since the electrophoretic peaks from CE are as narrow as $1 \mathrm{~s}$, a fast mass detector that can acquire the data with sufficient speed is required in order to maintain the quality of the total-ion electrophorogram (TIE) peaks and the high CE resolution. The system utilized in these experiments is an ion trap storage/ reflectron time-of-flight (IT/reTO F) mass spectrometer that is capable of acquiring a single mass spectrum at a speed of greater than $10 \mathrm{~Hz}{ }^{26}$ thus maintaining the separation efficiency of the CE. This is an important advantage in preserving high resolution separations coupled to mass analysis. In addition, the storage properties of the ion trap and the nonscanning nature of the IT/reTOF system result in a very high duty cycle even at the data acquisition rate required in these experiments. This method provides improved sensitivity in detection over a broad mass range for detection of low intensity signals in these CE separations.

\section{E X PE R IME NTA L}

\section{Preparation of $\mathbf{H b}$}

The $\mathrm{H} b$ protein was prepared in a manner similar to the method reported by Perrett et al. ${ }^{9} \mathrm{H}$ emolysates were prepared from blood by washing erythrocytes three times with an equal volume of normal saline buffer. Washed red cell samples $(0.5 \mathrm{~mL})$ were centrifuged to remove any additional impurities and the supernatant liquid was aspirated. The cells were lysed by diluting with $2.5 \mathrm{~mL}$ distilled water, and centrifuged at $8000 \mathrm{~g}$ for $15 \mathrm{~min}$ to isolate the cell membrane and other solid materials. The supernatant liquid was then added dropby-drop into a cold acid acetone (conc. $2 \%$ ) solution to precipitate the globin and to be dehemed; the tube was shaken vigorously during this procedure. A fter centrifugation at $3000 \mathrm{~g}$ for $10 \mathrm{~min}$, the supernatant liquid was removed and acetone was added to wash the precipitate. This procedure was repeated twice before the proteins were vacuum dried. The prepared globin was redissolved in deionized water for further use.

\section{Separation}

The separation of $\mathrm{Hb}$ chains was performed with an H PLC system (M odel Rabbit-HP, Rainin Instruments Co. Inc., Emeryville, CA, USA) using a $C_{18}$ $4.6 \mathrm{~mm} \times 30 \mathrm{~cm}$ column. The $\mathrm{Hb}$ chains were separated using a gradient from $45 \%$ to $55 \%$ acetonitrile containing $0.1 \%$ trifluoroacetic acid (TFA). Detection was performed using a UV absorption detector at $214 \mathrm{~nm}$ and the eluent was further identified by mass analysis. The sample was vacuum dried and tryptic digestion was applied to the $\alpha$ - and $\beta$-chains separately. Subsequently, the $\beta$-chains of both the normal and variant $\mathrm{H}$ bs were digested by TPCK -treated trypsin with a substrate to enzyme ratio (50:1) in $\mathrm{NH}_{4} \mathrm{HCO}_{3}$ solution at $\mathrm{pH} 8.4$ for 24 hours at $37^{\circ} \mathrm{C}$. The digests were then vacuum dried and reconstituted in the CE buffer.

Capillary electrophoresis was performed on a homebuilt apparatus using a $\pm 30 \mathrm{kV}$ high voltage power supply (Model CZE 1000R, Spellman High Voltage Electronics Corp., Plainview, NY, USA). In order to minimize the adsorption of peptides to the capillary wall, the inner wall of the capillaries was coated by a method similar to that described by M oseley and coworkers ${ }^{27}$ with minor modification. A $60 \mathrm{~cm}$ capillary (105 $\mu \mathrm{m}$ o.d., $40 \mu \mathrm{m}$ i.d.) was rinsed with $1 \mathrm{M} \mathrm{NaOH}$ solution for $4 \mathrm{~h}$, followed by flushing with $\mathrm{H}_{2} \mathrm{O}$ for $10 \mathrm{~min}, 5 \mathrm{M} \mathrm{HCl}$ solution for $30 \mathrm{~min}$, and $\mathrm{H}_{2} \mathrm{O}$ for another $10 \mathrm{~min}$. The capillary was then dried with pure nitrogen gas at $90^{\circ} \mathrm{C}$ overnight. Subsequently, it was washed with toluene for $30 \mathrm{~min}$ and $2.5 \%(\mathrm{v} / \mathrm{v}) 3$-aminopropyl-trimethoxy silane (APS) coating solution (toluene) was pumped through the capillary for $12 \mathrm{~h}$. The capillary was conditioned with the CE buffer for $4 \mathrm{~h}$ prior to use. The buffer used in all of the experiments was $10 \mathrm{mM}$ ammonium acetate with slightly varying $\mathrm{pH}$, depending on the different samples separated. A II of the CE separations were performed in the negative-ion mode with an electrical field strength of $\sim-300 \mathrm{~V} / \mathrm{cm}$. A variable wavelength UV detector (M odel SC 100, Thermo Separation Products, Fremont, CA , USA ) with the wavelength set at $198 \mathrm{~nm}$ was 
initially used to monitor the CE separation process. The samples were injected using the electrokinetic method which loads approximately 50-100 fmol protein digests for each run. The injection, separation, and data acquisition procedures were remotely controlled by a personal computer (Model P5-66, G ateway 2000 Inc., N. Sioux City, SD, USA ), where an ADC-16 analog board was applied to collect the UV signal at a frequency of $7 \mathrm{~Hz}$ where custom software controlled all procedures.

\section{O n-line sheathless CE/M S}

The mass spectrometer used in these experiments was an IT/reT O F system as described in previous work. ${ }^{28,29}$ It consists of a reflectron TOF mass analyzer ( $M$ odel $D$ 1450) coupled to a front end quadrupole ion trap storage device (M odel C-1251, R . M . Jordan C 0., G rass Valley, CA, USA). The pressures inside the ion trap main chamber and the TOF tube are $1 \times 10^{-5}$ Torr and $2 \times 10^{-7}$ Torr, respectively. In the IT/reTOF, ions are stored for a specific period of time in the ion trap with a preset $\mathrm{RF}$ voltage of $1100 \mathrm{~V}$ and a frequency of 1.1 $\mathrm{M} \mathrm{Hz}$ on the ring electrode. A helium buffer gas is added to the trap at a pressure of $\sim 10^{-3}$ Torr in order to enhance trapping of ESI-produced externallyinjected ions. Subsequently, a DC pulse voltage of $400 \mathrm{~V}$ is applied to the endcap of the trap to eject ions into the reTOF for mass analysis. I ons were detected by a $25 \mathrm{~mm}$ triple microchannel plate detector (Model C-2501, R. M. Jordan Co.).

The sheathless microelectrospray interface was constructed by using the capillary end as the electrospray needle as reported previously. ${ }^{30}$ B riefly, the capillary tip was etched from a dimension of $105 \mu \mathrm{m}$ o.d. to a fine diameter with concentrated hydrofluoric acid after $1 \mathrm{~cm}$ of polyimide coating had been removed. The outer surface of this tip was silver coated by using the electroless plating process, ${ }^{31}$ which includes degreasing in $\mathrm{CH}_{2} \mathrm{Cl}_{2}$, surface sensitization in a sensitizer solution,

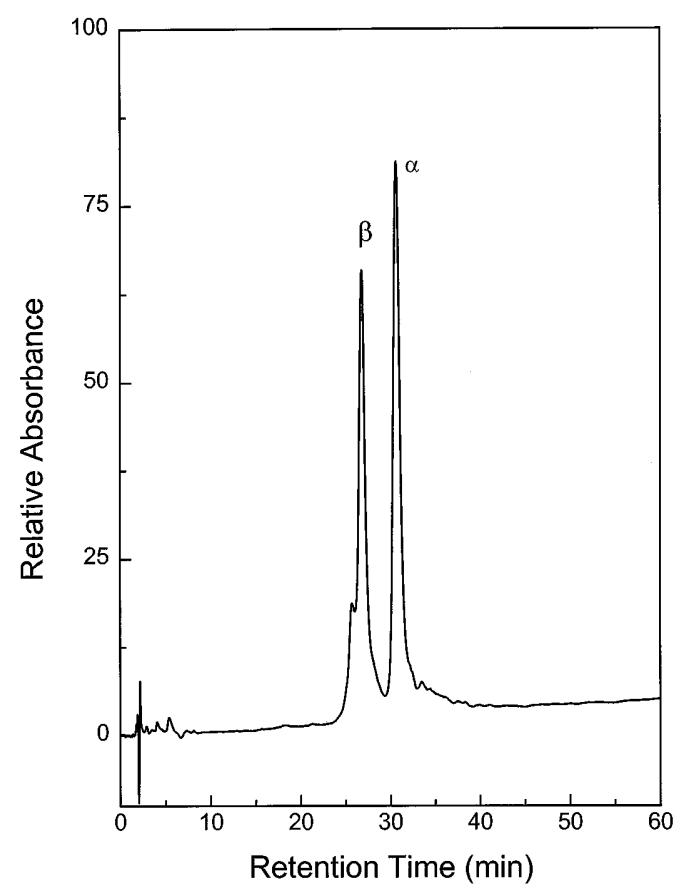

Figure 1. HPLC separation of $\mathrm{HbA}$ globin chains. Conditions: $\mathrm{C} 18$ column ( $30 \mathrm{~cm}, 4.6 \mathrm{~mm}$ i.d.), G radient: $45-55 \%$ acetonitrile containing $0.1 \%$ TFA in $60 \mathrm{~min}$. and finally insertion into the electro-plating solution of silver nitrate. This silver coating provided electric contact for both electrospray and capillary electrophoresis, by inserting the capillary tip into a $2 \mathrm{~cm}$ s.s. tube (125 $\mu \mathrm{m}$ i.d., $250 \mu \mathrm{m}$ o.d.) connected to the electrospray power supply. O ne end of the capillary was set at around $-13 \mathrm{kV}$, while the needle was at an electrospray voltage of $\sim 4 \mathrm{kV}$ so that the total $\mathrm{CE}$ separation voltage was around $-17 \mathrm{kV}$. The needle formed a stable electrospray plume with a resulting mass signal, provided the outer surface was periodically recoated with silver.

The mass signals were collected using a $250 \mathrm{M} \mathrm{Hz}$ transient recorder ( $M$ odel 9846, Precision Instruments Inc., Knoxville, TN, USA) embedded in a P5-66 personal computer, where the data processing was also conducted. This data acquisition system could acquire data at $25 \mathrm{~Hz}$ for a CE separation for over half an hour, using software developed in our laboratory. ${ }^{26} \mathrm{~A}$ timeof-flight expansion range of 0 to $150 \mu \mathrm{s}$, which corresponds to an $\mathrm{m} / \mathrm{z}$ range of $0-1500$, was generally used as the mass acquisition period. Mass calibration was performed using three standard peptides, viz. bradykinin, angiotensin I and L eu-E nk-A rg, according to the following equation, $(\mathrm{m} / \mathrm{z})^{1 / 2}=\mathrm{aT}+\mathrm{b}$, where $\mathrm{T}$ is the flight time.

\section{CID in the vacuum interface - skimmer region}

In order to detect the mutation site inside the specific fragment, CID of the CE-separated fragment was performed by raising the focusing lens voltage from $100 \mathrm{~V}$ to $150 \mathrm{~V}-200 \mathrm{~V}$. When the target digest fragment was about to elute from the capillary, the focusing lens voltage was rapidly increased in this way so that dissociation occurred in the region between the focusing lens and the skimmer.

\section{Mass analysis of H PL C -separated globin chains}

The confirmation of the mass values for the collected HPLC-separated $\mathrm{Hb}$ chains was performed by MALDI-MS using a linear time-of-flight mass spectrometer (R . M . Jordan C o.). The spectra were acquired using $355 \mathrm{~nm}$ radiation from a DCR -11 Nd:YA G laser system (Spectraphysics, M ountain View, CA, USA). The matrix used was $\alpha$-cyano-4-hydroxycinnamic acid, which was prepared in acetonitrile, deionized water and TFA (50:49:1). The mixture of protein and matrix (1:1) was placed on the probe tip and allowed to dry, before being subjected to mass analysis.

\section{Materials and chemicals}

A mmonium bicarbonate, TFA, ammonium acetate, acetonitrile, toluene, acetone, sodium hydroxide, hydrochloric acid, silver nitrate, formaldehyde, ammonium hydroxide, 3-aminopropyl-trimethoxy silane, angiotensin I, bradykinin, and Leu-E nk-A rg were purchased from Sigma (St. Louis, M O, U SA ). TPCK treated trypsin was purchased from Promega (M adison, WI, USA ). These materials were used without further purification. The water was filtered and deionized prior to use by a M illi-Q water purification system ( $\mathrm{M}$ illipore Corp., Bedford, MA, USA ). H bA was obtained from Sigma Co., while sickle cell anemia ( $\mathrm{HbS}$ ) and $\mathrm{HbE}$ samples were obtained as a gift from the World 
Laboratory (A nn A rbor, MI, U SA ). Fused-silica capillaries were purchased from Polymicro Technologies (Phoenix, A Z, USA).

\section{RE SU LTS A ND DISCU SSIONS}

The goal of this work is to pinpoint mutations in variant hemoglobins. In order to simplify this task we have chosen to separate the $\alpha$ - and $\beta$-chains of $\mathrm{Hb}$ before digestion so that the mutation can be initially identified as being in one or the other of the protein chains. The tryptic digestion of the $\alpha$ - and $\beta$-chains of $\mathrm{Hb}$ together provides 29 peaks, so that it is preferable to separate the proteins before digestion to simplify the assignment of the mutation. This becomes especially important in many variant $\mathrm{H}$ bs where the mutation may result in a mass difference of only $1 \mathrm{Da}$ or where minor chains, such as $\gamma$ - and $\delta$-chains, may be present and make the

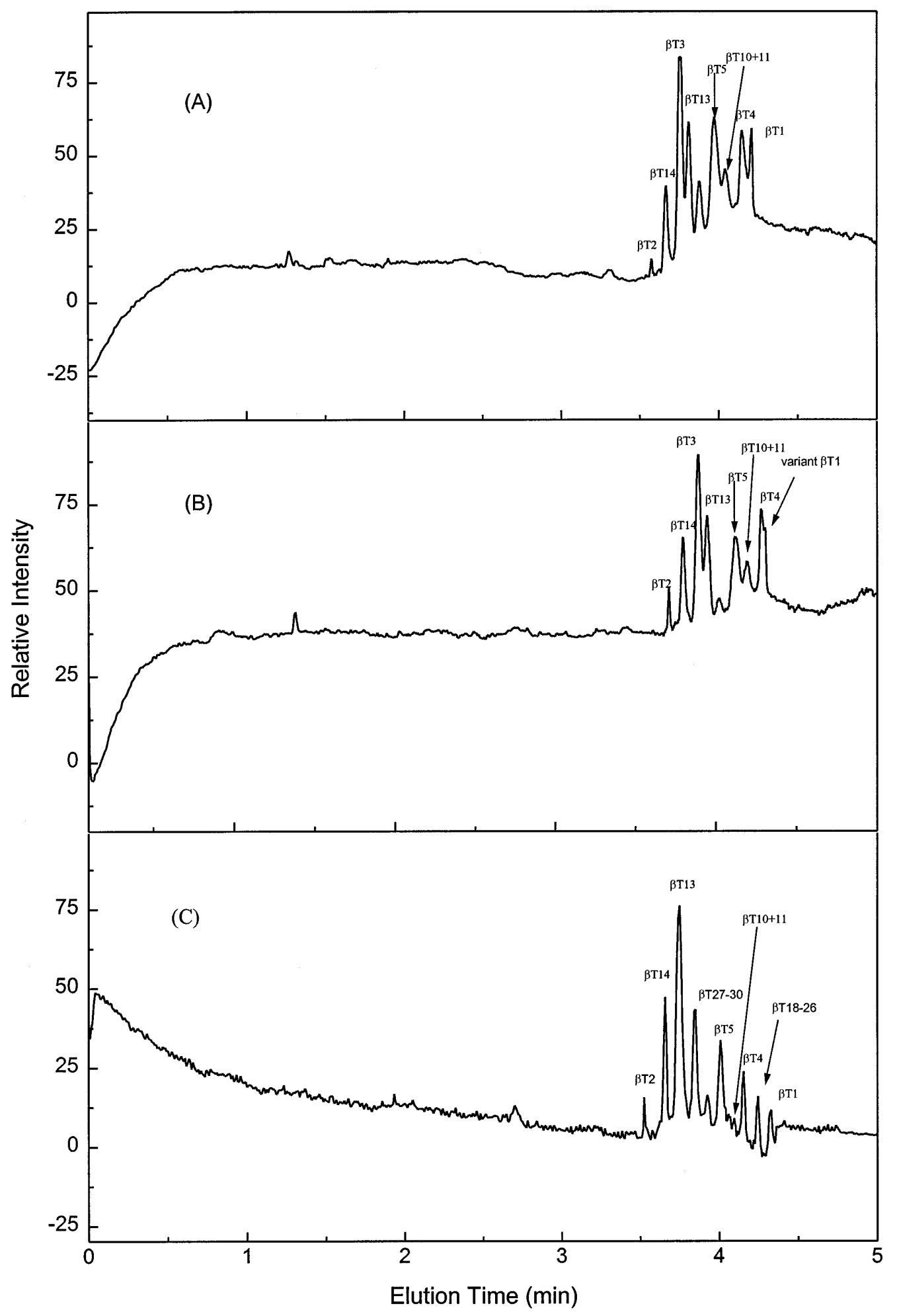

(A): $\mathrm{HbA},(\mathrm{B}): \mathrm{HbS},(\mathrm{C}): \mathrm{HbE}$

Figure 2. CE separation with $U V$ absorption detection of the $\mathrm{Hb}$ digests for (a) $\mathrm{HbA}$, (b) $\mathrm{HbS}$, (c) $\mathrm{HbE}$. Conditions: $V_{C E}=-17000$ V, Capillary: A PS coated, $60 \mathrm{~cm}, 40 \mu \mathrm{m}$ i.d., $105 \mu \mathrm{m}$ o.d. Buffer: $10 \mathrm{mM}$ ammonium acetate, $\mathrm{pH}=4.0$. 
resulting data particularly difficult to interpret for unknowns. In the case of the total digest separated by CE there may be as many as 10 peaks within a 1 min period and it would be difficult to distinguish abnormal from normal $\mathrm{Hb}$ using only total ion-electrophorograms in cases where only small variations in structure

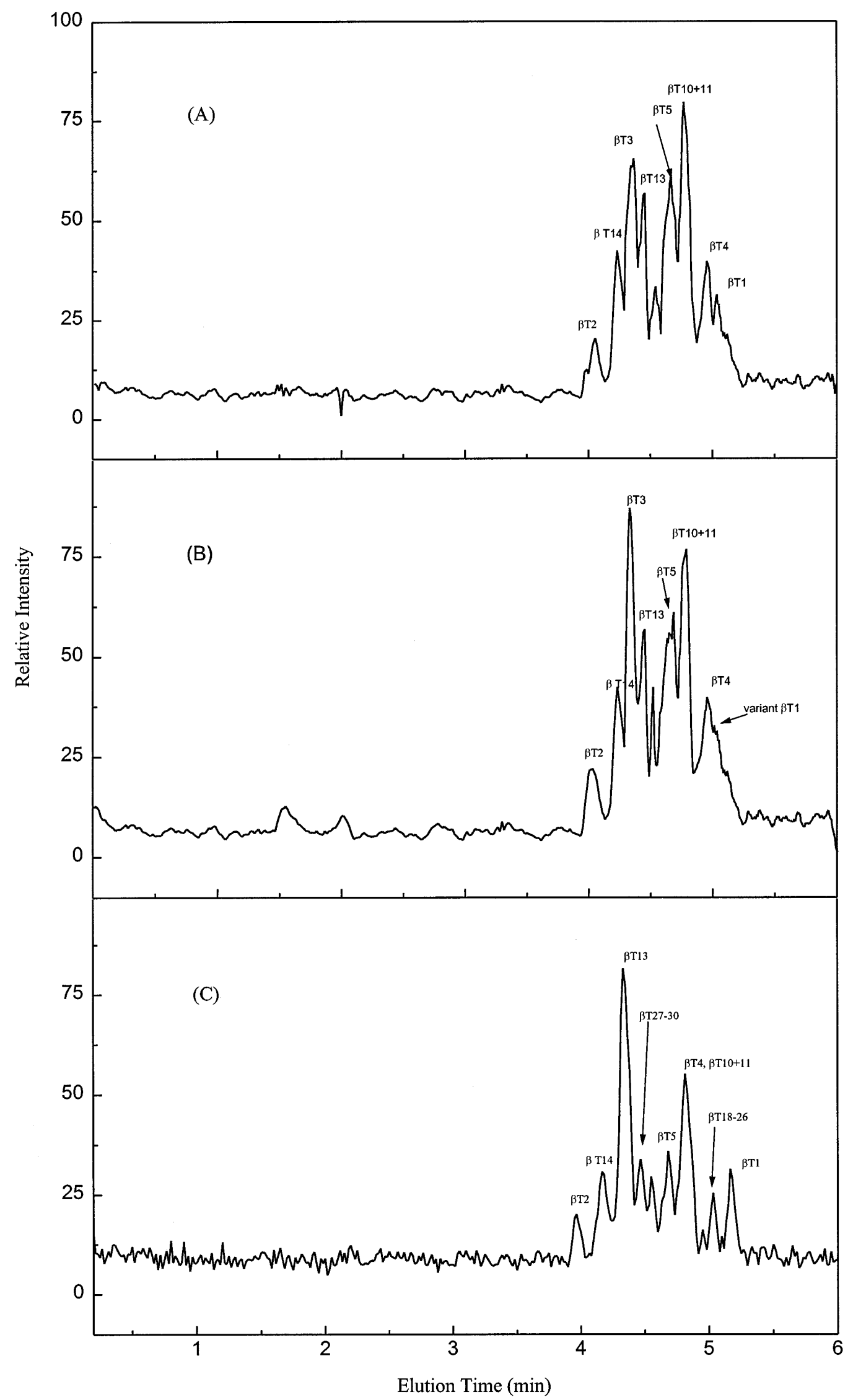

(A): $\mathrm{HbA},(\mathrm{B}): \mathrm{HbS},(\mathrm{C}): \mathrm{HbE}$

Figure 3. The TIE of the CE/M S of $\mathrm{Hb}$ digests for (a) $\mathrm{HbA}$, (b) $\mathrm{HbS}$, (c) $\mathrm{HbE}$. Conditions: $\mathrm{V}_{\mathrm{CE}}=-13000 \mathrm{~V}, \mathrm{~V}_{\mathrm{ESI}}$ $=4000 \mathrm{~V}$. O ther conditions are the same as those in Fig. 2. 


\begin{tabular}{|c|c|c|c|c|c|}
\hline Peptide & Sequence & $\begin{array}{c}\mathrm{m} / \mathrm{z} \\
\text { Calculated }\end{array}$ & $\begin{array}{c}\mathrm{m} / \mathrm{z} \\
\text { Observed }\end{array}$ & A ccuracy & $\begin{array}{l}\text { Migration time } \\
(\min )\end{array}$ \\
\hline$\beta \mathrm{T} 1$ & Val-H is-L eu-Thr-Pro-G lu'-G lu-Lys & 952.1 & 952.4 & $0.03 \%$ & 4.05 \\
\hline$\beta \top 2$ & Ser-A la-Val-Thr-A la-L eu-Trp-G ly-Lys & 932.1 & 932.3 & $0.02 \%$ & 4.23 \\
\hline ВТ3 & Val-A sn-Val-A sp-G lu-Val-Gly-G ly-G lu-A la-L eu-G ly-A rg & 1314.4 & 1314.1 & $-0.02 \%$ & 4.36 \\
\hline$\beta \top 4$ & L eu-L eu-Val-Val-Tyr-Pro-Trp-Thr-G In-A rg & 1274.5 & 1274.4 & $-0.01 \%$ & 4.46 \\
\hline$\beta \top 5$ & $\begin{array}{l}\text { Phe-Phe-G lu-Ser-Phe-G ly-A sp-L eu-Ser-Thr-Pro-A sp-A la-Val- } \\
\text { M et-G ly-A sn-Pro-Lys }\end{array}$ & 2059.3 & 2059.5 & $0.01 \%$ & 4.67 \\
\hline$\beta \top 6$ & Val-Lys & 245.3 & not detected & & \\
\hline$\beta \top 7$ & A la-H is-G ly-Lys & 411.5 & not detected & & \\
\hline$\beta$ ТТ 9 & $\begin{array}{l}\text { Val-L eu-G ly-A la-Phe-Ser-A sp-G ly-L eu-A la-H is-L eu-A sp- } \\
\text { A sn-L eu-Lys }\end{array}$ & 1669.9 & not detected & & \\
\hline$\beta \top 10+11$ & $\begin{array}{l}\text { L eu-H is-Val-A sp-Pro-G lu-A sn-Phe-A rg-L eu-H is-Val-A sp- } \\
\text { Pro-G lu-A sn-Phe-A rg }\end{array}$ & 2547.8 & 2546.4 & $-0.05 \%$ & 4.78 \\
\hline$\beta \top 13$ & G lu-Phe-Thr-Pro-Pro-Val-G In-A la-A la-Tyr-G In-Lys & 1378.5 & 1378.2 & $-0.02 \%$ & 4.95 \\
\hline BТ 14 & Val-Val-A la-G ly-Val-A la-A sn-A la-L eu-A la-H is-Lys & 1149.4 & 1149.5 & $0.01 \%$ & 5.03 \\
\hline$\beta \top 15$ & Tyr-H is & 318.3 & not detected & & \\
\hline
\end{tabular}

Calculated $\mathrm{m} / \mathrm{z}$ values:

${ }^{a} \mathrm{H}$ bS: The substitution of glutamate in $\mathrm{HbA}$ by valine causes the resulting fragment to be found at $\mathrm{m} / \mathrm{z} 922.1$, with a migration time at 4.98 $\min$.

${ }^{b} \mathrm{HbE}$ : The substitution of glutamate by lysine in this peptide results in an additional cleavage point under tryptic digestion. The resulting two fragments have $\mathrm{m} / \mathrm{z}$ values of 916.0 ( $\beta$ T 18-26, eluting at $5.04 \mathrm{~min}$.) and 415.5 ( $\beta$ T 27-30, eluting at $4.47 \mathrm{~min}$.), where the total of the two digest products is 1331.5 .

were involved. A Ithough a mass spectrometer detector can detect these small differences, interpretation will be complicated by co-eluting peaks and other unseparated background contaminants.

Figure 1 shows the separation of the $\alpha$ - and $\beta$-chains of $\mathrm{Hb}$ using $\mathrm{HPLC}$ with $\mathrm{C} \mathrm{C}_{18}$ column $(30 \mathrm{~cm} \times 4.6 \mathrm{~mm})$ and gradient elution (45-55\% acetonitrile in $60 \mathrm{~min}$ ). The $\alpha$-chain is observed at $30.63 \mathrm{~min}$. and the $\beta$-chain at $26.82 \mathrm{~min}$. A number of minor peaks, which are also observed in the chromatogram, were not identified but could result in background in our experiment if not separated out using HPLC. This separation was performed with $\sim 10 \mu \mathrm{g}$ of initial sample. $\mathrm{A} \mathrm{C}_{18}$ column was used in the HPLC separation as opposed to the $C_{4}$ column used in earlier work by Shelton. ${ }^{6}$ It was found that the use of $C_{18}$ resulted in some sample loss, but that the $\mathrm{C}_{4}$ column applied in these experiments did not provide a satisfactory separation. The eluent was fraction collected following separation and the mass confirmed by MALDI-MS. The $\beta$-chains for various $\mathrm{H}$ bs were determined as $\beta^{A}$ (normal $\mathrm{Hb}$ ), $\mathrm{m} / \mathrm{z} 15867$; $\beta^{\mathrm{S}}$ (sickle-cell anemia), $\mathrm{m} / \mathrm{z} 15$ 837; and $\beta^{\mathrm{E}}, \mathrm{m} / \mathrm{z} 15$ 866, respectively. In addition, the collected fractions of the small background peaks were also subjected to mass analysis so that their presence in the $\beta$-fraction could be monitored.

Following separation of the globin chains of $\mathrm{Hb}$ by H PLC, the fraction was dried and subjected to trypsin digestion. The $\beta$-chain digests were then separated by $\mathrm{CE}$ and initially detected by UV absorption detection. In Fig. 2 is shown the CE electrophorograms of the tryptic digests of the $\beta$-chains of three forms of $\mathrm{Hb}$. In Fig. 2(a) is shown the electrophorogram of normal hemoglobin as the standard and in Fig. 2(b) and (c) are shown the electrophorograms of the $\beta$-chains of $\mathrm{HbS}$ and $\mathrm{HbE}$ respectively. A Ithough the el ectrophorograms are similar, there are clearly differences in the profiles. Peaks that are different from the $\mathrm{HbA}$ standard and suspected of containing a mutation site are marked by an arrow. The variation in the $\mathrm{H}$ bs may only be a single amino acid, as in these cases, where the chain variations in $\mathrm{HbS}$ and $\mathrm{HbE}$ are $\beta 6$ (G lu $\rightarrow$ Val) and $\beta 26$ (Glu $\rightarrow$ Lys), respectively. Nevertheless, the use of CE can successfully separate and discriminate between the small changes in digest peaks. In these cases such separation may be due to the change in charge distribution, since glutamate is negatively charged while valine is basically neutral and lysine is positively charged at neutral $\mathrm{pH}$. The sharp separations demonstrate that the coating on the capillary inner surface provides a positive layer that repels the peptide successfully under the acidic conditions. The separation generally was on the order of $1.5 \times 10^{4}$ theoretical plates in these experiments. The optimum separation varied depending on the buffer $\mathrm{pH}$ and the concentration of the samples and the migration times also varied somewhat according to the conditions. $\mathrm{N}$ evertheless, relatively similar electrophorograms can be observed for the different $\mathrm{Hb}$ variants as expected.

In comparison, in Fig. 3 is shown the total-ion electrophorogram of $\mathrm{Hb}$ digest obtained using on-line CE/M S. M ost of the peaks observed correspond to the CE separation with UV absorption detection of Fig. 2. There are some differences in terms of peak width and migration times. The differences in migration times observed in CE/M S versus U V absorption detection were due to the UV detector window being situated $6 \mathrm{~cm}$ before the capillary anode. The slightly broader peak width in the TIE can be explained, according to $M \mathrm{CL}$ afferty and coworkers, ${ }^{32}$ by the fact that when the capillary tip was exposed to atmosphere during electrospray, the solvent was easily evaporated due to the small needle dimension. This evaporative effect at the capillary tip subsequently induces a flow inside the capillary. F urthermore, it was demonstrated by $M$ ann, 33 and later by M CL afferty, ${ }^{32}$ that the electrostatic drawing of the buffer solution and sample by the electric field between the needle and the transit stainless steel capillary results in a constant flow in the direction of electrospray, even without the addition of the CE voltage. Nevertheless, it is noteworthy that more than 10 peaks in the electrophorogram were separated in 1-2 min and the entire separation was completed in less than 6 min where many of the peaks are as narrow as 1-2 s. The TIE s of Fig. 3 illustrate the capability of the 
IT/reTOF to acquire spectra for even the fastest separation. The non-scanning characteristics of the IT/ reTOF, allows data acquisition at a rate of 0.04 s/spectrum, limited ultimately by the data system. In these experiments, a $0.25 \mathrm{~s}$ data acquisition time was used in order to compromise between preserving the CE resolution and the mass sensitivity. In Table 1 is listed a comparison of the calculated and observed mass values of the tryptic digests of $\mathrm{H} \mathrm{bA}$ in the CE/M S experiment.

In Fig. 4 are shown the mass spectra corresponding to the $\mathrm{T} 1$ digest products of $\mathrm{HbA}$ and $\mathrm{HbS}$. A s reported in
Shackleton's ${ }^{17}$ earlier experiments in the LC/M S of hemoglobin digests, the major E SI-produced ions of the $\mathrm{Hb}$ protein digests were doubly-charged. Such doublycharged ions are indeed observed as shown in Fig. 4 and can be confirmed as being doubly-charged using the resolution of the IT/reTOF where the relative separation of the isotopic peaks in the doubly-charged ions is half that of the singly-charged ions, as expected. We examined the mass spectra of the particular TIE peaks that appear to shift between the analysis of $\mathrm{HbA}$ and $\mathrm{HbS}$. This mutation site was substantiated by the mass spectra where a mass shift of $\mathrm{m} / \mathrm{z} 15$ was observed for

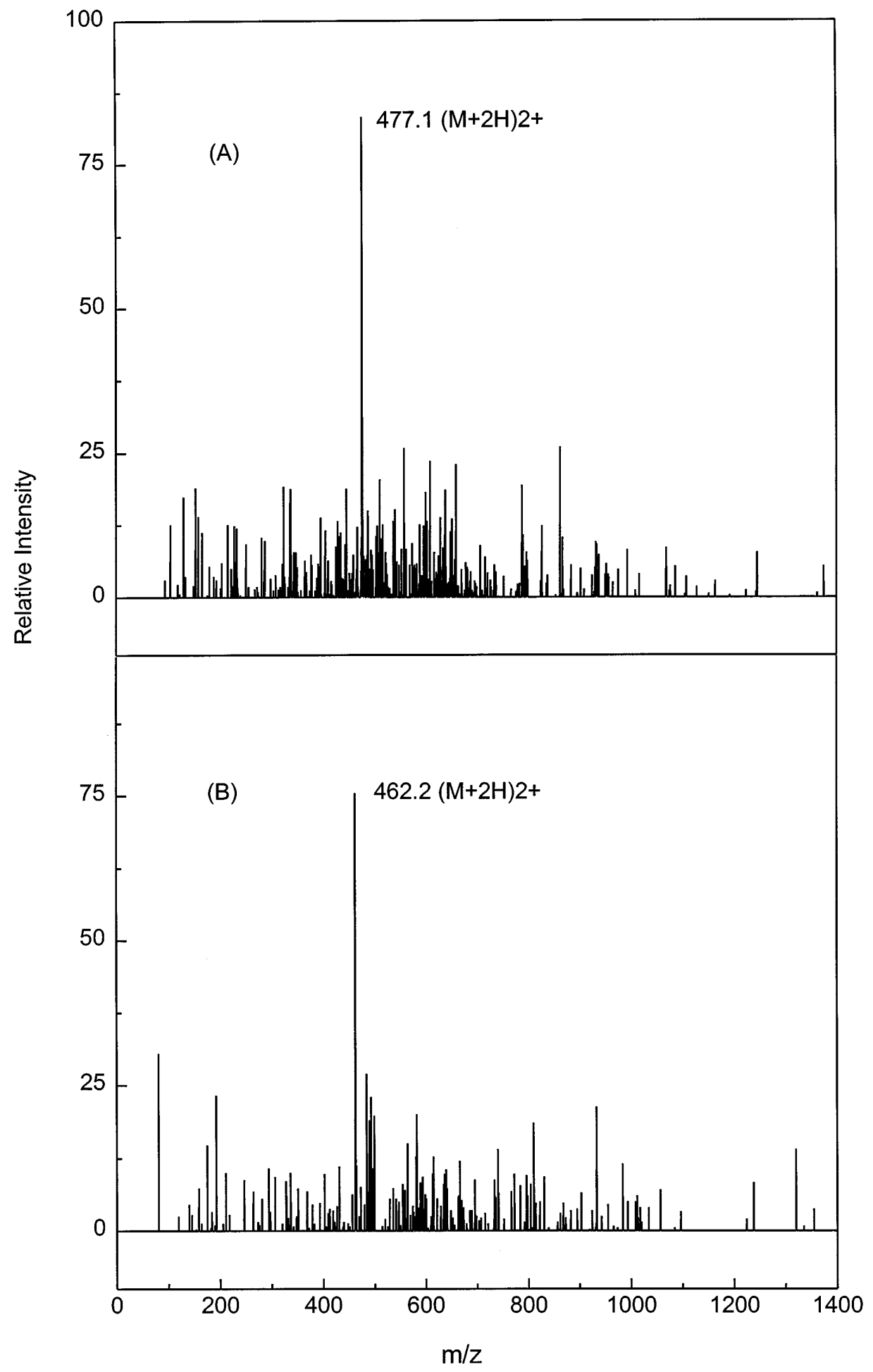

Figure 4. $M$ ass spectra of the $\beta T 1$ fragment in $\mathrm{HbA}$ and $\mathrm{H}$ bS obtained in $\mathrm{CE} / \mathrm{M} \mathrm{S}$ experiment (a) $\mathrm{H} \mathrm{bA}$ $\beta T 1$ fragment, (b) HbS variant $\beta$ T 1 fragment ion. Single mass spectrum acquisition time: $0.25 \mathrm{~s}$, $\mathrm{V}_{\text {Focusing Lens }}=100 \mathrm{~V}$. 
doubly-charged ions. This corresponds to a mass shift of 30 , which is expected for the substitution of glutamate by a valine. The mass resolution in these experiments is $\sim 2000$ and the mass error is less than $0.05 \%$ as shown in Table 1. Thus, it appears that this method clearly demonstrates the expected mutation site and identity of this sample as sickle cell anemia.

In the $\mathrm{HbE}$ electrophorogram with $\mathrm{UV}$ detection and in the TIE of Figs 2 and 3, there were several additional digest peaks observed compared to the case of $\mathrm{HbS}$ and $\mathrm{HbA}$. Since the glutamate is substituted by a lysine in the $\mathrm{HbE}$, it would be expected that trypsin would cut the protein in this position resulting in two additional fragments. In a comparison of the mass spectral data of the CE separation of the tryptic digests of $\mathrm{HbA}$ and $\mathrm{HbE}$, two extra peaks at $\mathrm{m} / \mathrm{z} 916$ and $\mathrm{m} / \mathrm{z}$

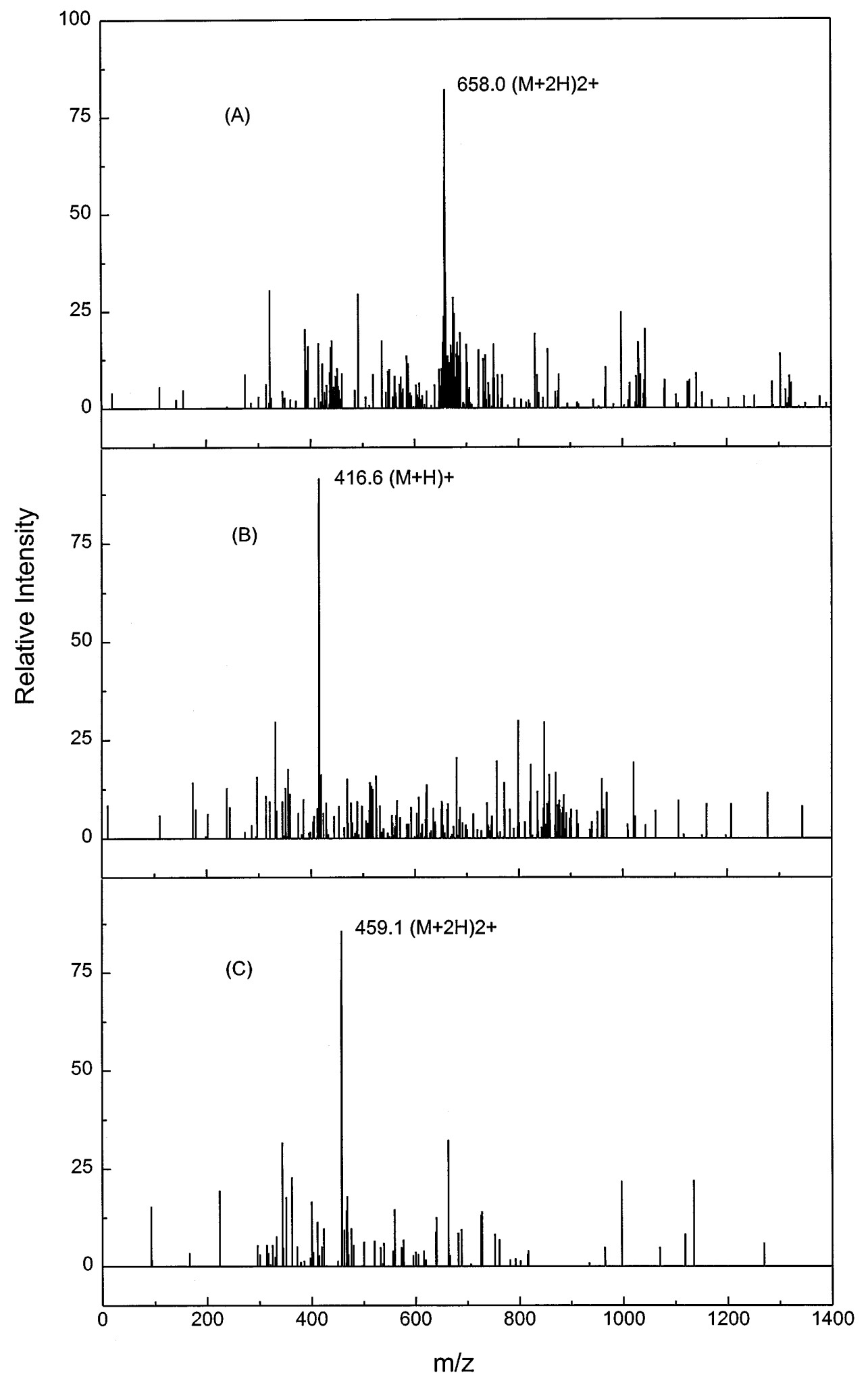

Figure 5. M ass spectra of the $\beta T 3$ fragment in $\mathrm{HbA}$ and corresponding fragments in $\mathrm{HbE}$ obtained in $\mathrm{CE} / \mathrm{MS}$ experiment where (a) corresponds to $\mathrm{HbA} \beta \mathrm{T} 3$ fragment ion, (b) to H bE $\beta \mathrm{T} 27-30$ fragment, and $(c)$ to $\mathrm{H}$ bE $\beta$ T 18-26 fragment. These two fragment ions result from the tryptic digestion at the lysine residue at $\beta 26$ position in $\mathrm{HbE}$. 
415.5 were observed in $\mathrm{HbE} \beta$-chain, which correspond to the $\beta 18-26$ and $\beta 27-30$ fragments, respectively. The sum of these two fragments is equal to 1331.5 , which is the mass value of the $\beta$ T 3 peptide plus a water molecule if this lysine position was not cleaved by trypsin. The mass spectra for these fragments are shown in Fig. 5.

In order to pinpoint the mutation site detected in these specific fragments, collision-induced dissociation was performed for the $\mathrm{H}$ bS $\beta T 1$ fragment in the region between the focusing lens and skimmer. A Ithough this method can not isolate the parent ion for fragmentation, the CE separation provided a preselection for the specific ions. Shackleton et al. previously recorded CID data from $\mathrm{Hb}$ variants by changing the nozzle-toskimmer voltage and inducing considerable fragmentation in the parent ion. ${ }^{18}$ In the present experiment, when the $\beta \mathrm{T} 1$ was about to elute from the capillary in the second run, immediately following the initial CE / MS experiment, the focusing-lens voltage was raised from $100 \mathrm{~V}$ to between $150 \mathrm{~V}$ and $200 \mathrm{~V}$. In Fig. 6 (b) is shown the H bS $\beta$ T 1 fragment CID spectrum. This was obtained using a storage time of $0.5 \mathrm{~s}$ and signal averaging the spectrum at least eight times. Thus, a total effective time of $4 \mathrm{~s}$ was used to examine the CID spectrum. A $n$ increase in storage time was needed to enhance the signal-to-noise ratio in these experiments. In the spectrum, the dominating fragment ions are of the $y$ - and $b$ - series. The $y_{3}$ and $y_{6}^{2+}$ ions are 30 mass units less than those in the $\mathrm{HbA}$ (see Fig. $6(\mathrm{a})$ ), as a result of the substitution of the glutamic acid by valine (Val-H is-L eu-Thr-Pro-Val-Glu-Lys vs. Val-H is-LeuThr-Pro-G lu-G lu-Lys) whereas the $\mathrm{y}_{1}, \mathrm{y}_{2}$, and $\mathrm{b}_{2}$ ions are the same as those in $\mathrm{HbA}$, as expected. From these data, it is quite clear that the $\beta 6$ position is where the substitution occurs.

\section{CONCLUSION}

CE/ESI using an IT/reTOF mass detector has been used to provide a rapid and sensitive method for analyzing structural variants in hemoglobin. Tryptic digests of variant $\mathrm{H}$ bs have been analyzed by this method in which a comparison of the TIEs and mass spectra of the mutant and normal $\mathrm{H}$ bs can detect the presence of the mutation site. In addition, CID in the vacuum interface - skimmer region has been used to pinpoint the identity of such a site in $\mathrm{HbS}$, following

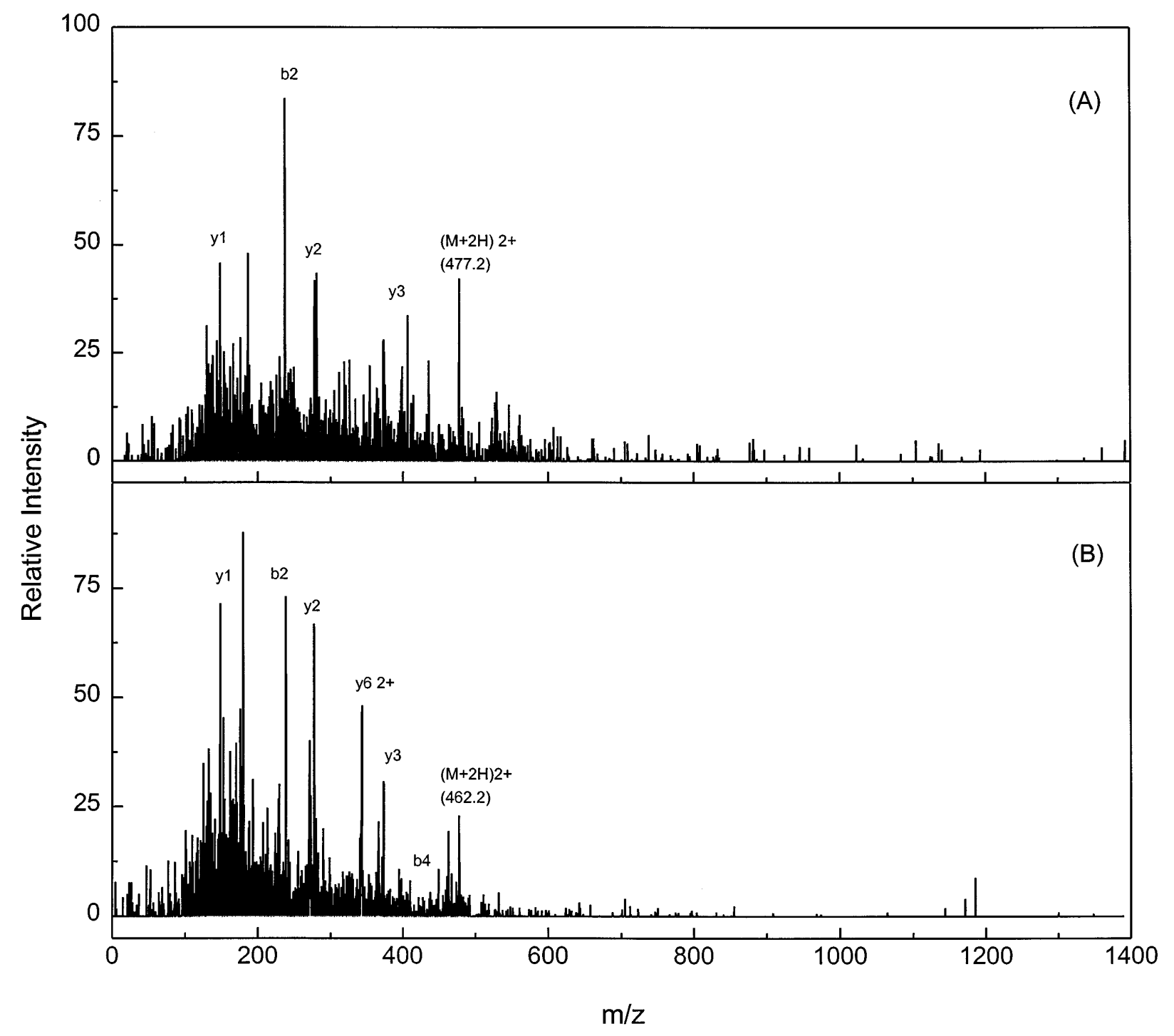

(A): $\mathrm{HbA} \beta T 1$ (B): $\mathrm{HbS} \beta T 1$

Figure 6. CID spectra of the $\beta T 1$ fragment in (a) $\mathrm{HbA}$ and (b) $\mathrm{HbS}$ during the CE/M S experiment. 
separation of the peptide digest fraction by $C E$. The CE /E SI - IT/reT OF/M S method is shown to have unique capability for efficiently and accurately detecting fast separations with narrow peaks that may be under $1 \mathrm{~s}$ FWHM. The speed of this system is critical for the isolation of the large number of peaks that must be separated in a short time duration in these CE experiments.

\section{A cknowledgements}

We gratefully acknowledge support of this work by the $\mathrm{National}$ Institutes of $\mathrm{H}$ ealth under G rant Number R 01G M 49500 and partial support of this work from the A rmy/ERDEC under Grant N umber DA A D 05-95-9-3517. M. X. L. would also like to thank the Protein Core Facility Center at the U niversity of Michigan M edical Center for the use of their HPLC system to separate the globin chains, and D r A nthony K illeen of the Clinical D iagnostics $L a b$ at the $U$ niversity of Michigan Medical Center for providing the patient hemoglobin samples.

\section{REFERENCES}

1. V. M. Ingram, Nature 178, 792 (1956).

2. International $\mathrm{H}$ emoglobin Information Center L ist, $\mathrm{H}$ emoglobin 18, 77 (1994).

3. B. B. R ogers, R. A. Wessels, C. N. O u and G. Buffone, J. A m. J. Clin. Pathol. 84, 672 (1985).

4. P. B asset, Y. B enzard and M. C. G arel and J. R osa, B lood 51, 971 (1978).

5. L. F. Congate and A. G. Kendall, A nal. Biochem. 123, 124 (1982).

6. J. B. Shelton, J. R. Shelton and W. A. Schroeder, J. Liquid Chromatogr. 7, 199 (1984).

7. S. A bbes, P. A . Fitzgerald, E. Varady, R. G irot, P. Pic, Y. B louquit, R. Ducrocq, F. Grupt and H. Wajcman, Hemoglobin 19, 173 (1995).

8. S. R ahbar, Hemoglobin 10, 379 (1986).

9. G. A. Ross, P. Lorkin and D. Perrett, J. Chromatogr. 636, 69 (1993)

10. J. W. Jorgenson and K. D. Luckas, J. Chromatogr. 218, 209 (1981).

11. M. J. Gordon, X. Huang, S. L. Pentoney, Jr. and R. N. Zare, Science 242, 224 (1988).
12. M. Casragbola, I. M essana, L. Cassiano, R . R abino, D. V. R ossetti and B. G iardina, Electrophoresis. 16, 1492 (1995).

13. C. Ong, L. S. Liau and H. Y. Ong, J. Chromatogr. 576, 346 (1992).

14. T. M atsuo, Biomed. M ass Spectrom. 8, 25 (1981).

15. P. Ferranti, A. Malorni, P. Pucci, S. Fanali, A. Nardi and L. O ssicini, A nal. Biochem. 194, 1 (1991).

16. T. R. Covey, E. C. H uang and J. D. H enion, A nal. Chem. 63, 1193 (1991).

17. C. H. Shackleton and H. E. Witkowska, A nal. Chem. 68, 29A (1996).

18. H. E. Witkowska, F. Bitsch and C. H. Shackleton, Hemoglobin 17, 227 (1993).

19. M. T. D avis, T. D. Lee, M. R onk and S. A . H efta, A nal. Biochem. 224, 235 (1995).

20. P. Juhasz, I. A. Papayannopoulos, C. Zeng, V. Papov and K $B$ iemann. In Proceedings of the 40th $A$ nnual Conference on $M$ ass Spectrometry and Allied Topics, 31 May-5 June, 1992, Washington, D. C., p.1913, A SM S, Santa Fe (1992).

21. K. J. Light-Wahl, J. A . L oo, C. G. Edmonds, R. D. Smith, H. E. Witkowska, C. H. Shackleton and C. C. Wu, Biomed. Mass Spectrom. 22, 112 (1993).

22. T. Nakanishi, M. K ishikawa, A . Shimizu, A . H ayashi and F. Inoue, J. M ass Spectrom. 30, 1663 (1995)

23. H. E. Witkowska, B. N. Green, M. M orris and C. H. Shackleton, J. Mass Spectrom. and Rapid Commun. Mass Spectrom. S111 (1995).

24. M. Sakairi, Rapid Commun. M ass Spectrom. 7, 1108 (1993).

25. D. Promé, J. C. Promé, C. D éon, P. G roff, G. K Imes, F. G alacteros and $\mathrm{H}$. Wajcman, J. M ass Spectrom and Rapid Commun. M ass Spectrom. S165 (1995).

26. M. G. Qian, J.-T. Wu, S. Parus and D. M. Lubman, Rapid Commun. M ass Spectrom. 10, 1209 (1996)

27. M. A . M oseley, J. W. J orgenson, J. Shabanowitz, D. F. H unt and K. B. Tomer, J. A m. Soc. M ass Spectrom. 3, 289 (1992).

28. S. M. M ichael, B. M. Chien and D. M. Lubman, R ev. Sci. Instr. 63, 4277 (1992).

29. M. G. Qian and D. M. Lubman, A nal. Chem. 67, 234A (1995).

30. J.-T. Wu, M. G. Qian, M. X. Li, L. Liu and D. M. Lubman, A nal. Chem. 68, 3388 (1996).

31. G. O. M allory and J. B. H ajdu, E lectroless P lating: Fundamentals and A pplications, A merican E lectroplaters and Surface Finishers Society (1990).

32. G. A. Valaskovic and F. W. M CL afferty, Rapid Commun. Mass Spectrom. 10, 825 (1996).

33. M. S. Wilm and M. Mann, Int. J. M ass Spectrom. Ion Processes 136, 167 (1994). 